\title{
Los lunes al sol. Retrato social de historias de vida silenciadas
}

\author{
Mondays in the Sun. A social Portrait of Silenced Lives' Stories
}

DIANA AMBER*

JESÚS DOMINGO**

"UNIVERSIDAD DE JAÉN. * UNIVERSIDAD DE GRANADA

Artículo recibido el / Article received: 01-09-2015

Artículo aceptado el / Article accepted: 10-08-2016

RESUMEN: La película Los lunes al sol ha tenido un fuerte impacto emocional y social en el colectivo de mayores de 45 años en desempleo. Numerosas iniciativas de acceso al empleo para los mayores la usan como referente reivindicativo. El estudio busca la comprensión de la imagen que el film ofrece sobre los desempleados mayores, con objeto de analizar las actitudes y experiencias de los personajes frente al desempleo y del propio imaginario social sobre esta temática. La metodología utilizada es el análisis fílmico desde una vertiente discursiva y analítico-reflexiva, centrada principalmente en el análisis del hecho discursivo del film. Los resultados se centran en los entresijos personales, sociales y laborales de sus personajes. Describen e interpretan las escenas y escenarios más representativos que componen y estructuran las historias narradas. Las principales conclusiones apuntan hacia la virtud del film para visibilizar la problemática y dignificar al colectivo desde la autocrítica social de esta realidad.

Palabras clave: cine, desempleo, trabajadores mayores, retrato social.

ABstract: The film Mondays in the sun has had a strong emotional and social impact on the group of unemployed people over 45 years old. Numerous initiatives for access to employment for older people use it as a protest reference. The study looks for understanding the image the film offers about older unemployed, in order to analyze the attitudes and experiences of characters from unemployment and the social imaginary itself on this issue. The methodology used in the filmic analysis from a discursive and analytic-reflexive viewpoint, mainly focused on the discursive fact analysis of the film. The results focus on the personal, social and labour intricacies of his characters. They describe and interpret the most representative scenes and stages that integrate and structure the different stories narrated by the film. Main conclusions point out to film's virtue for 
making difficulties clearly visible and dignifying the collective from the social self-criticism of this reality.

Keywords: cinema, unemployment, older workers, social portrait.

\section{JUSTIFICACIÓN Y PUNTO DE PARTIDA}

La película Los lunes al sol, dirigida por Fernando León de Aranoa en 2002, se ambienta en los años posteriores a la reconversión industrial, en la entrada del siglo XXI. El contexto en el que se desenvuelve la historia es previo a la importante crisis económica que sufre España en la actualidad y que tan graves consecuencias en la estabilidad financiera, social y psicológica de muchas personas y familias está teniendo. La historia relata las vidas de un grupo de compañeros de trabajo años después de su despido de los astilleros en Vigo. Se centra en la repercusión que la pérdida de empleo ha tenido en sus vidas, así como en sus casuísticas personales y en los rumbos tomados por los diferentes personajes.

Forma parte de un conjunto de films que invitan a la reflexión durante la primera década del siglo XXI, que tematizan, o de otras maneras, transmiten las circunstancias de creciente desigualdad social de hoy. Tanto desde perspectivas honestas y realistas, sin dramatismos y teatralizaciones, como desde visiones más ácidas y críticas. Asunto del que se ocupa Carlo Testa (2013), desde el primer enfoque, hablando de la sociedad desempleada en Italia, o, desde el segundo, Bullot (2014) cuando ironiza sobre el desempleado en manos de la modernidad líquida que anunciara Bauman (2007).

Esta perspectiva de crítica cinematográfica parte de la visión del cine como espejo y modelo planteada por Sell, Martínez-Pecino y Loscertales (2014). En este estudio, entendemos que el cine no solo representa la realidad, sino que goza de influencia sobre ella. El claro poder de legitimación del cine permite normalizar y formar creencias y educar en valores (McQuail, 2000). A su vez, su alta capacidad de sugestión, mediada por una fiel y dramática representación de la realidad, que puede llegar a asimilarse como una experiencia vivida (Méndiz, 2008), llevan al espectador en ocasiones a identificarse con los personajes de la historia. Luego, el cine es un material importante para repensar y contrastar la realidad y la identidad personal y profesional; como catalizador de debate crítico-dialéctico a partir de un particular retrato social (Calatayud, 2013) o hipótesis de realidad (Ponga, Martín y Torreiro, 2002), que repasa el 
imaginario social (Imbert, 2010), con un matiz sensibilizador y de concienciación, comprometido con la acción social.

Estas reacciones sociales desatan el interés hacia el estudio de esta película, que radica en la fuerte influencia que está teniendo sobre el colectivo de mayores de 45 años en desempleo. Estas personas han tomado al film por bandera como contraejemplo, pues muestra formas de vida a las que no se quieren acercar y con las que no se quieren identificar, ni ser identificadas. Las mayores alusiones y usos sociales de la película nacen más de 10 años después de la creación de esta, una vez adentrados en la crisis económica. La precariedad laboral que caracteriza a los personajes, genera adversidad por parte de movimientos sociales y asociaciones hacia la identificación con estos perfiles profesionales y de vida, que usan el film como modelo a evitar.

En 2013 nace el blog No quiero ser portada de los lunes al sol, ${ }^{1}$ dejando su huella también en redes sociales como Twitter y Facebook, y pretendiendo ser una vía de escape del desempleado y un mediador de oportunidades de acceso al empleo. El propio nombre del blog declara el reto de sus creadores y seguidores de alejar sus vidas y experiencias emocionales y profesionales de las precarias historias vividas por los protagonistas del film.

Los creadores de este blog no son los únicos que se apoyan en la imagen de la película en sus acciones sociales y reivindicativas. La Asociación de Mayores Parados por el Empleo de Baleares (AMPEB) apostó en 2014 por la campaña «No queremos más lunes al sol» en la que pretendían dar visibilidad a la problemática y reclamar soluciones. Esta iniciativa tuvo bastante repercusión mediática en la prensa española, siendo noticia en algunos diarios de tirada nacional como El Mundo ${ }^{2}$ y La Vanguardia. ${ }^{3}$

Esta película ha sido objeto de estudios centrados en su análisis pragmalingüístico (García-Álvarez, 2005; Liverani, 2005) y desde un enfoque sociológico y político (Lozano, 2015) y jurídico (Ferreiro, 2008), por lo que, aun considerando y partiendo de estos planteamientos, este estudio aborda el análisis desde la óptica de los sentimientos y actitudes asociados al desempleo que se muestran en el film, a partir de las distintas respuestas sociales que tienen los personajes frente a una situación prolongada de desempleo.

1. Blog disponible en: http://noquieroserpls.blogspot.com.es/.

2. Noticia disponible en: http://www.elmundo.es/baleares/2014/06/29/53b02b5be2704e3e3a8b 457d.html.

3. Noticia disponible en: http://www.lavanguardia.com/local/islas-baleares/20140713/54411068261/ los-parados-mayores-de-45-anos-continuaran-este-lunes-con-la-campana-no-queremos-maslunes-al-sol.html. 
Marzal (2007: 68) asegura que la naturaleza del cine «no solo es entretener sino también ayudarnos a comprender mejor la realidad que nos ha tocado vivir». Apoyándonos en sus palabras, la principal contribución de este trabajo es la comprensión de la imagen que la película ofrece sobre el desempleo en los mayores de 45 años, conscientes de su influencia en este colectivo y de su gran repercusión en la generación de iniciativas sociales que la usan como anti-modelo.

\section{METODOLOGÍA}

Partimos de que no existe un método universal para el análisis de films (Aumont \& Marie, 2002). Por tanto, este estudio diseña su propia estrategia apoyándose en las corrientes existentes de exploración discursiva y analíticoreflexiva, que se centran en desentrañar las emociones y respuestas al desempleo que se representan en el film y que han dejado su huella en la sociedad. Se estudia la película, tanto en sus aspectos formales como temáticos, con vistas a ahondar en los personajes y situaciones propuestas en ella, y que pueden ayudar a explicar y poner en cuestión el discurrir errático y disfuncional de la sociedad contemporánea (Campillo, Sáez y Zaplana, 2013).

El propio diseño de la película Los lunes al sol en el que numerosas historias fragmentadas, basadas en casualidades y encuentros se entrecruzan a lo largo del film sin centrar el argumento (Quintana, 2003; García-Álvarez, 2005), invita a la descomposición de la historia en unidades narrativas significativas para el estudio. Siguiendo a Delponti (2007) estas unidades se analizan con una mirada transversal en secciones temáticas, obviando la cronología del film y prevaleciendo las relaciones y vínculos entre las historias narradas.

En pos del logro de la finalidad de este estudio, el análisis del «hecho fílmico» (Delponti, 2007), se centra más en el hecho discursivo (referido al contenido), que en el hecho estético (referido a la forma, las imágenes, los planos...) -aunque este coadyuva al primero-, por tanto, se utiliza como método principal el análisis del discurso audiovisual, desde un enfoque cualitativo (narrativo-dialéctico). De esta forma el análisis se orienta al discurso relacionado con la experiencia del desempleo de los protagonistas, así como a la expresión de sus sentimientos, emociones y actitudes asociadas a este hecho, sirviéndonos del poder del cine como «medio artístico para representar retazos de la vida cotidiana» (Calsamiglia \& Tusón, 1999: 2), desde los que repensar la realidad. 


\section{RESULTADOS}

La descomposición de la historia fílmica en unidades narrativas nos permite organizar los resultados del estudio en cinco bloques. Centrados en los cinco personajes principales de la película, muestran cinco maneras muy alejadas de enfrentar el despido y cinco rumbos de vida unidos por un mismo acontecimiento traumático y un fuerte vínculo emocional.

\subsection{La esquina de Amador}

El caso de Amador es, sin duda alguna, el más duro de los que se narran en la historia. Hombre reservado, de pocas palabras y con una profunda dependencia de la bebida. Personaje con pocas intervenciones, protagonista de planos secundarios y ebrio en casi todas sus escenas y diálogos, quiere representar la caída más profunda a la desesperación y la desesperanza, así como el desgate emocional que causa una situación prolongada de desempleo.

$\mathrm{Su}$ fuerte sentimiento de abandono se manifiesta claramente hacia la mitad de la película en una divagación producida en parte por este sentimiento que le envuelve y en parte por la excesiva toma de alcohol. En este contexto y desde su esquina de la barra del bar, Amador se cuestiona si Dios cree en ellos:

La cuestión no es si nosotros creemos o no en Dios, la cuestión es si Dios cree en nosotros, porque si no cree en nosotros... estamos jodidos. No sé si me estoy explicando. Y yo creo que no cree, por lo menos en mí no cree... ${ }^{4}$

Sus palabras delatan la depresión y el hundimiento del personaje, el vacío que siente, sabiéndose olvidado por la sociedad y creyéndose también en el olvido de Dios.

El desempleo le sume en un encierro que le aleja hasta de la búsqueda de apoyo en sus compañeros, a quienes no confiesa el abandono de su mujer y las condiciones insalubres de su vivienda. Generando barreras y temas tabú (como la ausencia de su mujer, motivo de varias trifulcas y desaires) que evitan a lo largo de la película que los compañeros puedan conocer su situación y prestarle ayuda y apoyo. Tal desmoronamiento anímico y reclusión emocional, acompañadas de una fuerte dependencia del alcohol, llevan al personaje al suicidio.

4. Todas las citas textuales incluidas en el apartado «Resultados» pertenecen al film Los lunes al sol (León de Aranoa, 2002). 
Destaca entre su lenguaje encubierto y esquivo, el uso de la metáfora de los siameses, en una escena en la que su amigo Santa le acompaña a casa debido a su incapacidad para tenerse en pie a causa del consumo de alcohol. Esta metáfora es interpretada por Santa en una de las escenas finales de la película, haciendo alusión a la unión y conexión que hay entre ellos y cómo el perjuicio de uno repercute en el resto. Este mensaje evoca al poder de la unión en el logro de objetivos, por lo que tiene matices reivindicativos implícitos.

Amador es el único personaje que tiene asignado un espacio físico en el escenario del bar, que se hace tan suyo que le representa. Esta esquina es mucho más que un simple espacio, es un recurso metafórico que simboliza la marginación y aislamiento social que el personaje sufre. Es un rincón que le aparta y a la vez le resguarda a modo de coraza de la interacción con el mundo.

Tanta es la compenetración entre el lugar y el personaje, que una de las escenas finales, aun sin saber que él había fallecido, sus compañeros hablan de él señalando su esquina vacía. En este contexto, Santa apunta a Rico: «Tú has cogido este bar y te va bien, y yo me alegro. Pero otros no han tenido tanta suerte: Amador, por ejemplo... [Y señala su esquina vacía]».

Tras el suicidio de Amador, muy sentido por parte de sus compañeros del bar, y el velatorio al que solo ellos acudieron (acentuando la soledad del personaje), llevan la urna con sus cenizas al bar. En la escena del bar, la urna está situada en la esquina de Amador, sobre la barra. Cuando se plantean qué hacer con ella, José propone: «Podíamos dejarla ahí en su esquina». Ante la irónica negativa de Rico, José añade: «Total, se pasaba ahí la vida». Esta afirmación de su compañero refuerza la imagen de perniciosa rutina y declive asociada al personaje, que se encuentra en un bucle de aislamiento y depresión del que solo siente el espejismo de escapar fugazmente a través del alcohol, y del que se libera finalmente con el suicidio.

\subsection{Yo no soy el sujeto activo}

La vida de José se mece entre la rutina y la incertidumbre que los problemas en su matrimonio le generan. Este personaje convive con dos desvelos que le atormentan, por un lado, el desempleo, vivido como una situación crónica para la que no busca salida. Y por otro, los problemas con su mujer, causados en gran medida por el primero.

El personaje sufre una fuerte contradicción en cuanto a la situación laboral de su mujer. Consciente de la necesidad del sueldo de su esposa, acepta, aunque sin agrado, que ella trabaje fuera. $\mathrm{Su}$ inconformidad con la situación se 
muestra en varias escenas de la película. En el pasaje en el que los compañeros se reúnen para ver el fútbol clandestinamente, ante el afán de Reina por limpiar todo rastro de su paso por allí, José le propone con ironía «podías pasarte un día por casa y recoges un poco, que está todo hecho un asco». Este comentario de José desencadena una conversación que revela el evidente desagrado que el empleo de su mujer le genera:

Lino: Eso es porque la tuya (su mujer) trabaja fuera.

José: ¿Tú, qué pasa? ¡Que eres muy listo!

Lino: Solo he dicho que trabaja fuera y trabaja fuera, ¿no?

José: Pues sí, ¿qué pasa?

Lino: Nada, $\mathrm{j} . .$. , es que parece que te molesta.

Santa (voz en off): Es que le molesta.

Las fuertes connotaciones machistas que marcan la personalidad de José generan un sentimiento de insuficiencia en él y un complejo de inferioridad respecto a su esposa, que deriva en constantes conductas ofensivas hacia ella y hacia los demás.

$\mathrm{Su}$ potestad en actos cotidianos, como la solicitud de un crédito, queda mermada a causa del desempleo. La indiferencia con la que el director del banco le trata (centrándose en el sujeto activo, su mujer) crea una escena que recrea, apoyándose en un juego de miradas y expresiones de los personajes, la impotencia y la ansiedad sufrida por José al quedar palpablemente al margen de tal asunto financiero. Las exaltadas e irónicas palabras de José a su mujer tras abandonar la entidad financiera en una acalorada e hiriente discusión, desvelan los demonios internos del personaje: «Ah, claro, es que yo no soy el sujeto activo. Total ¿yo quién soy? Nadie, un g... que no vale para nada. Si acaso para que se rían de él en su p... cara».

La creencia arraigada por parte del personaje de que el hombre debe sustentar económicamente el hogar, así como su propio sentimiento de incompetencia y culpa, generan disputas, controversias y rencores que toman parte en la historia de su matrimonio, severamente dañado ante la pasividad del personaje.

A pesar de la angustia que el desempleo le genera, José se muestra paralizado en la rutina, sin esperanzas ni intención de cambiar. Esta actitud se manifiesta no solo hacia el empleo, sino también en otros aspectos de su vida, como en la relación con su mujer. Especialmente indicativo de esta actitud es el comentario que José le hace a Santa cuando su mujer le propone que hablen a su vuelta del trabajo: «Yo no quiero hablar, yo quiero que siga todo igual». 
El miedo a que su mujer le abandone, es un fantasma que le acecha a lo largo de la película y que se hace más evidente al final de esta. Una maleta escondida desvela al espectador las intenciones de su esposa. Sin embargo, la conmoción por la muerte de Amador y el relato por parte de su esposo de las circunstancias de soledad y encierro que le llevaron a quitarse la vida, consternan a su mujer, que con solo el gesto de ocultar el equipaje a su esposo revela al público la continuidad del matrimonio.

\subsection{Queriendo teñir los años}

Paulino (o Lino), como le llaman sus compañeros, es un hombre constante, sereno, con gesto afligido en gran parte de sus escenas y evasivo de conflictos y reyertas. Su tenacidad es subrayada desde el inicio de la historia en su continua búsqueda de trabajo en las oficinas de empleo, hasta tres años después del cierre de los astilleros.

El peso de la familia le impulsa a no perder ocasión, aunque haya perdido el ánimo. Sus irreflexivos y desorientados esfuerzos por lograr un puesto de trabajo le llevan a solicitar a ciegas cualquier oferta laboral, independientemente de sus requerimientos y exigencias. Al inicio de la película, en uno de sus trayectos en barco hacia una entrevista laboral, una conversación con sus compañeros desvela la inadecuación de su perfil a la oferta a la que aspira. Justifica con dudosas réplicas (que ni a él mismo convencen) todos los requisitos que expone la oferta, y que José y Santa le cuestionan: vehículo propio (que no tiene y espera comprar) y conocimientos de informática (cuyo hijo le está enseñando), desviando siempre el tema hacia a las atractivas condiciones laborales del contrato y queriendo obviar las discordancias. Tan solo manifiesta abiertamente preocupación por uno de los requisitos cuando afirma: «Lo único la edad, que tiene límite: 35», creando unos segundos de incómodo silencio entre sus compañeros, conscientes de que él rondará los 50 años.

Además de su falta de información sobre el puesto, del que reconoce hasta no saber de qué se trata, destaca la actitud de desánimo con la que se enfrenta a la entrevista, asegurando con voz apocada: «pero si yo ya pienso que no me lo van a dar».

A pesar de su falta de acierto para la elección de ofertas laborales y su desconcierto en cuanto a estrategias de búsqueda de empleo, que denotan una imperiosa necesidad de orientación laboral, Lino es el único personaje que muestra cierto interés hacia el reciclaje y la actualización profesional, al intentar acercarse a las nuevas tecnologías, con ayuda de su hijo. 
Destacan las escenas de Lino sentado en la oficina de empleo a la espera de su turno, mirando con abatimiento y desesperanza a su alrededor, mientras se compara con los candidatos más jóvenes que aguardan su oportunidad. $\mathrm{Su}$ preocupación por la edad, como barrera para el acceso al empleo, y la alusión a sus canas por parte de Santa como evidencia de sus años en conversaciones anteriores, llevan al personaje a afrontar la siguiente entrevista con un cambio de imagen. Eligiendo un vestuario, a su juicio, más juvenil y tiñendo su cabello en el aseo del barco, camino a la entrevista.

Lejos de surtir el efecto rejuvenecedor deseado, el oscuro tinte se desliza por su cuello segundos antes de que sea llamado a la entrevista. Un melancólico acompañamiento musical de guitarra, acrecienta y traslada al espectador el sentimiento de angustia y desolación del personaje, mientras busca desesperadamente y sin éxito, un pañuelo para limpiar el tinte que escurre por su cuello.

Las continuas experiencias de fracaso en sus repetidos intentos de lograr un empleo, y el desánimo y la desesperanza generados por estas empujan al personaje al término de la película a renunciar a su búsqueda.

\subsection{La cigarra y la hormiga}

Rebelde, tunante y descarado, el personaje de Santa representa el lado más revolucionario del desempleo. Cabecilla de numerosas revueltas ante el cierre del astillero, continúa años después con pleitos a causa de estas.

Libre de cargas familiares, vive la situación de desempleo de una forma menos frustrante desde su soltería. En apariencia es el personaje menos afectado psicológicamente por el desempleo, pero a la vez es el más comprometido por la defensa de los derechos y la dignidad laboral, no solo propia, sino también de sus compañeros. Entiende siempre la lucha social desde la unión necesaria para tener una mayor fuerza, y es el único que mantiene su espíritu de rebelión social, tras tres años en desempleo.

En todo momento, aun con un marcado carácter sarcástico y despreocupado, defiende y reivindica los derechos de los trabajadores y denuncia la injusticia cometida con ellos. Esto se muestra en una escena en la que Santa acompaña a José mientras este mantiene una conversación con el altivo administrativo del astillero, que le comenta la dificultad para encontrar las nóminas después de tantos años. Santa interviene de fondo preguntado: « $i \mathrm{Y}$ la vergüenza? ¿La habéis encontrado ya o tampoco? Porque podemos llamar a las 200 familias que habéis dejado en la calle para que os ayuden a buscarla». 
A pesar de sus continuas muestras de desfachatez y descaro, Santa manifiesta gran empatía y complicidad con sus compañeros, siendo un buen consejero y un fiel amigo.

Con una actitud de tajante activista, se revela contra las desigualdades sociales en cualquiera de sus formas y manifestaciones. Estas impulsivas reacciones se observan en muchas escenas. Destaca el pasaje en el que Santa, junto a sus compañeros, cuida de un niño de cuatro años de forma clandestina para conseguir algún dinero. Al acostar al pequeño, la lectura de la fábula $L a$ cigarra y la hormiga aviva su vena reivindicativa. Los cambios de tono de su voz durante la lectura, así como sus comentarios, delatan su desacuerdo con la historia. La lectura del final de la fábula, en el que la hormiga niega su ayuda a la cigarra y deja que esta pase hambre y frio durante el inverno, despierta la ira de Santa. Exaltado, tacha a la hormiga de «especuladora» y defiende a la cigarra basando sus argumentos en la existencia de desigualdades sociales y en la falta de oportunidades, mientras el niño le observa con cautela y confusión.

El marcado carácter reivindicativo de Santa choca de frente con el de Reina, uno de los personajes con los que comparten momentos y diálogos en el bar. Reina defiende abiertamente los peores estereotipos del parado en España, con comentarios que provocan a Santa, tales como: «Bueno me voy... a trabajar, Santa, a manteneros con mis impuestos.». O: «A mí me sacan todos los meses una pasta de la Seguridad Social para mantener a una panda de vagos». Las constantes acusaciones e indirectas de Reina abren una discusión con Santa, pasado el ecuador de la película, que desvelan al espectador los tortuosos derroteros que llevaron a cada personaje a su situación actual. Santa recuerda cómo junto a sus compañeros defendieron años atrás sus derechos frente a la amenaza del cierre del astillero, asegurando: "Conseguimos que se enterara la gente.». A lo que apunta Reina: «Pues ya se les ha olvidado a todos.». Y añade Santa: «Y conseguimos estar juntos, eso a mí no se me ha olvidado.». Este diálogo con tonos de disputa acerca al público a la compresión de los personajes y al origen del entramado fílmico.

\subsection{Salir a flote sin barco}

No todos los trabajadores que fueron despedidos del astillero están en desempleo. Rico, el dueño del bar en el que siempre se reúnen, sale a flote diariamente con ayuda de su taberna, a la que acuden principalmente sus compañeros. 
Este personaje no participa habitualmente en las actividades que sus compañeros realizan fuera del bar (tomar el sol a la orilla del mar, ver el fútbol, etc.), ni se relata su vida al margen de este. Esta exclusión de las escenas de recreo, salvo de las reuniones en el bar, que en su caso son trabajo, le muestran como un hombre absorto en su empleo y familia, y recalcan aún más la desocupación laboral del resto.

No se trata de un personaje principal de la película, sus intervenciones son puntuales y no se narran historias que lo protagonicen. Tan solo a raíz del enfrentamiento final entre Reina y Santa, sale a la luz cómo Rico invirtió en su bar el dinero que logró como indemnización al ser despedido de los astilleros.

Aunque Rico no se posiciona habitualmente en las disputas, ante los comentarios de Santa sobre cómo finalmente y a pesar de la unión inicial entre los trabajadores, el ofrecimiento de un convenio a los fijos logró dividirlos, Rico reacciona afirmando: «Para ti es fácil decirlo, Santa, tú no tenías hijos, ni mujer. Pero los que teníamos casi 50 años, ¿qué? ¿Quién nos iba a contratar? ¿Otro astillero?».

Sus palabras desvelan el temor hacia el despido a su edad y la creencia de que no podrá volver a trabajar por cuenta ajena en otra empresa, lo que le lleva a firmar el convenio que retrasa un año su salida. Este mismo miedo empuja a optar por el emprendimiento como alternativa laboral, que resulta exitosa gracias, en parte, al apoyo de sus conocidos.

\section{DISCUSIÓN DE LOS RESULTADOS Y CONCLUSIONES}

La película recrea con contundencia y dureza el lado más amargo del desempleo. Los juegos de luces, hilos musicales y escenarios intensifican la precariedad del barrio y las desventuras de sus protagonistas. En Los lunes al sol personajes con temperamentos y caracteres muy dispares se enfrentan a un mismo acontecimiento social (Cruz-Cámara, 2010), coincidiendo con la película Barrio del mismo director (Léon de Aranoa, 1998). Las diferentes personalidades representadas en el film muestran reacciones y actitudes frecuentes ante el desempleo que se escenifican y que pueden lograr la identificación del espectador con sus personajes. Cabe señalar que la película solo narra historias de hombres en desempleo, por lo que existe un sesgo en la representación de las mujeres en esta situación de precariedad laboral, compartido por la industria cinematográfica en general. La historia con protagonistas femeninas transcurriría probablemente por derroteros muy diferentes, centrados en el entorno doméstico y el cuidado del hogar (Poveda, 2006). 
En el film todos los protagonistas en desempleo se ven envueltos por un sentimiento de desánimo, falta de motivación hacia la búsqueda de empleo y una baja autoestima que empeora su situación, tendencia común en los desempleados de larga duración (Rubio, 2013). En casos extremos este sentimiento puede tornar en depresión e incluso en suicidio (Milner, Page, \& LaMontagne, 2013), representado claramente en el film a través de Amador.

La frustración sufrida por la impotencia ante la situación, deriva con frecuencia en respuestas ofensivas por parte del desempleado (Santos, 2006), que se escenifican principalmente a través de algunas reacciones de José y Santa durante la película.

En las historias cruzadas en el film se distinguen cinco réplicas o reacciones diferentes ante la pérdida del empleo, tras años de profesión y una identidad profesional ya creada (Dubar, 2002):

- Por una parte, destaca la postura reivindicativa de Santa (De la Rosa, 2014), cuyos principios le instan a una lucha social constante en cualquier entorno.

- En segundo lugar, el conformismo, la resignación y la renuncia a la búsqueda ante a una situación vivida y sentida como irremediable, especialmente marcadas en la historia de Amador, aunque también presentes en menor medida en José.

- Los sentimientos de insuficiencia e inferioridad generados por la pérdida de empleo presentes en José se acrecientan por la inadaptación a los nuevos roles de género presentes en su familia. En este sentido, vive el empleo de su mujer como un ataque a su masculinidad, incapaz de replantearse las relaciones de género con su pareja (Téllez \& Verdú, 2011).

- De especial interés para este estudio es el caso de Lino, único personaje interesado en el reciclaje profesional y en mejorar su formación y competencias profesionales como vía de acceso al empleo (Thieme, Brusch, Büsch, \& Stamov, 2015), aunque claramente desorientado en su búsqueda.

- Por último, se refleja a través de Rico el cambio de sector profesional por medio del emprendimiento, como alternativa laboral, motivado tan solo por la necesidad y la falta de empleo.

Las respuestas ante el desempleo de los personajes que llevan años sin trabajar delatan falta de autoeficacia (Lang \& Lee, 2005), pues estos son incapaces de conocer sus potencialidades y destrezas adquiridas en su experiencia anterior 
y extrapolarlas a otros contextos profesionales. Por ejemplo, la historia de Lino y sus indiscriminadas solicitudes laborales, desvelan escasez de autoeficacia, pues sus elecciones de ofertas de empleo no se ajustan a su perfil profesional y, por tanto, sus posibilidades de éxito se reducen. La desorientación laboral de los personajes también descubre la carencia de oportunidades de formación permanente y para la inserción laboral a las que tienen acceso: desconocen cómo afrontar una entrevista de trabajo, a qué ofertas pueden acceder, cómo mejorar su perfil profesional, etc. Problemática abordada en el estudio de Sanhueza (2013), que evidencia las bajas oportunidades de formación a lo largo de la vida que existen para las personas mayores.

El aislamiento social de los personajes, así como algunos comentarios entretejidos en los diálogos, indican el silenciamiento del colectivo de desempleados mayores (Füredi, 2004), que se muestran en el film como personas en el olvido social. Precisamente contra este silencio, se revelan en la actualidad las asociaciones que reivindican los derechos de los desempleados mayores de 45 años, que se apoyan en la película en su lucha y que han motivado este análisis. No obstante, no se descarta que en casos concretos, la visualización del film cree identificación emocional con los personajes y genere un sentimiento de abatimiento que refuerce la falta de motivación hacia la búsqueda de empleo y el aislamiento personal.

Estos flujos de influencia, que inciden en espectadores de variopintas mentalidades, así como los enfoques y matices abordados en este análisis, nos invitan a cerrar este trabajo planteando al lector la reflexión en torno al interrogante que cuestiona si el film actúa como una fuente de inspiración reivindicativa, o como un modelo de resignación para el espectador. En cualquier caso, una película controvertida, cognitiva y socialmente desafiante, que denuncia una dramática realidad personal, laboral y social ante un futuro inquietante e incierto.

Concluyendo, el trabajo de Fernando León de Aranoa ayuda a tomar conciencia de que este colectivo existe, tiene su orgullo y dignidad, y merece ser visibilizado y tomado en consideración, frente a la falta de expectativas actuales, al cómodo silencio y el insidioso olvido en el que se encuentra actualmente. 


\section{REFERENCIAS BIBLIOGRÁFICAS}

Aumont, J.; M. Marie (2002): Análisis del film, Barcelona, Paidós.

BAuman, Z. (2007): Tiempos líquidos, Barcelona, Tusquets Editores.

Bullot, F. (2014): «L'usine vide comme imaginaire cinematographique», Contemporary French and Francophone Studies, 18(3) : 314-322. DoI: 10.1080/17409292.2014.906217

Calatayud, E. (2013): «Crisis y retrato social en el cine español contemporáneo: estudio caso de Fernando León de Aranoa», Revista F@ro, 2(18): 61-76.

Calsamiglia, H.; A. Tusón (1999): Las cosas del decir. Manual de análisis del discurso, Barcelona, Ariel Lingüística.

Campillo, M.; J. Sáez; A. Zaplana (2013): «Nuevos lenguajes fílmicos en la vieja Europa: el cine social de los hermanos Dardenne», Fotocinema. Revista cientifica de cine y fotografía, 6: 97-121.

Cruz-Cámara, N. (2010): «El simulacro desde el extrarradio: barrio de F. León de Aranoa», Bulletin of Spanish Studies: Hispanic Studies and Researches on Spain, Portugal and Latin America, 82(1): 59-73. DoI: 10.1080/1475382052000331114.

DE la Rosa, J. N. (2014): «Del "Que se vayan todos" al "No nos representan". Respuestas a la crisis económica en Argentina y España», Ágora, 1(2): 101-116. DoI: 10.6035/Kult-ur.2014.1.2.5.

Delponti, P. (2007): «Cómo analizar una película: a propósito de La Historia Oficial», Área abierta, 18: 1-15.

DuBAR, C. (2002): La crisis de las identidades. La interpretación de una mutación, Barcelona, Edicions Bellaterra.

Ferreiro, C. (2008): «Los lunes al sol y la explicación del derecho del trabajo», Dereito, 17(1): 91-105.

FüREDI, F. (2004): Therapy culture: Cultivating Vulnerability in an Uncertain Age, Nueva York, Psychology Press.

García-Állvarez, A. (2005): "Análisis pragmalingüístico de Los lunes al sol», Media and Communication Studies, 68: 1-21.

IMBERT, G. (2010): Cine e imaginarios sociales, Madrid, Cátedra.

LANG, J. C.; C. H. LEE (2005): «Identity accumulation, others' acceptance, job-search self-efficacy, and stress», Journal of Organizational Behavior, 26: 293-312. DoI: 10.1002/job.309.

León de Aranoa, F. (dir.) (1998): Barrio [película], Madrid, Elías Querejeta $\mathrm{y}$ otros.

- (dir.) (2002): Los lunes al sol [película], Madrid, Elías Querejeta y otros. 
Liverani, E. (2005): Los lunes al sol: apuntes para un análisis «pragmalingüístico». In AISPI, Actas XXIII (pp. 291-312). Madrid: Centro Virtual Cervantes.

Lozano, M. J. (2015): «Los lunes al sol: consecuencias perversas de la flexibilidad productiva», en RodRíGuez, A. (ed.) (2015): España en su cine: aprendiendo sociología con películas españolas, Madrid, Dykinson. 165177.

Marzal, J. (2007): «El análisis fílmico en la era de las multipantallas», Comunicar. Revista Científica de Comunicación y Educación, 29 (xv): 63-68.

MCQuaIL, D. (2000): McQuail's Mass Communication Theory, Londres, Sage.

Méndiz, A. (2008): La influencia del cine en la familia, Málaga, Universidad de Málaga.

Milner, A.; A. Page; A. D. LaMontagne (2013): «Long-term unemployment and suicide: a systematic review and meta-analysis», PLOS ONE, 8(1): 1-6. Dor: 10.1371/journal.pone.0051333.

Ponga, P.; M. A. Martín; C. Torreiro (2002): Hipótesis de realidad. El cine de Fernando León de Aranoa, Melilla, Consejería de Cultura de la Ciudad Autónoma de Melilla / UnED-Melilla.

Poveda, M. M. (2006): «"Los lunes al sol” o "Los lunes en casa”. Roles de género y vivencias del tiempo de desempleo», Cuadernos de Relaciones Laborales, 24(2): 85-110.

Quintana, A. (2003): «La realidad digital o algunas propuestas sobre el camino hacia el ensayo fílmico», Quaderns del CAC, 16: 3-8.

Rubio, F. J. (2013): «Tengo 50 años ¿y qué? Dificultades y estrategias en el retorno al mercado de trabajo», Nómadas. Revista Crítica de Ciencias Sociales y Jurídicas, 40(4): 93-109. DoI: 10.5209/rev_NOMA.2013.v40. $\mathrm{n} 4.48338$.

SANhueza, J. (2013): «Educación permanente y para la ciudadanía en Chile: un paradigma distinto y una promesa incumplida para las personas mayores», Foro de Educación, 11(15): 229-240. Dor: 10.14516/ fde.2013.011.015.011.

SANTos, O. (2006): «Nas margens de dentro: Um projeto para desempregados», en Lima, L. C. (ed.) (2006): Educaçao não escolar de adultos. Iniciativas de educaçao o formaçao em contexto associativo. Braga, Universidade do Mihno. 149-177.

Sell, L.; R. Martínez-Pecino; F. Loscertales (2014): «El cine como herramienta educativa para abordar la violencia en las aulas», Píxel-Bit. Re- 
vista de Medios y Educación, 45: 111-124. DoI: 10.12795/pixelbit.2014. i45.08.

TéLlez, A.; A. D. Verdú (2011): «El significado de la masculinidad para el análisis social», Revista Nuevas Tendencias en Antropología, 2: 80-103.

Testa, C. (2013): «Crisis-What crisis? The jobless society and Italian cinema in the early 2000», Forum Italicum, 47(1): 126-149.

Thieme, P.; M. Brusch; V. Büsch; C. Stamov (2015): «Work context influences on older workers' motivation for continuing education», Zeitschrift für Erziehungswissenschaft, 18(1): 71-87. DoI: 10.1007/s11618014-0600-8. 